\title{
Economic Loan Loss Provision and Expected Loss
}

Stefan Hlawatsch, Department of Banking and Finance, Otto-von-Guericke University Magdeburg, E-mail: stefan.hlawatsch@ovgu.de Sebastian Ostrowski, Department of Banking and Finance, Otto-von-Guericke University Magdeburg, E-mail: sebastian.ostrowski@ovgu.de

\begin{abstract}
The intention of a loan loss provision is the anticipation of the loan's expected losses by adjusting the book value of the loan. Furthermore, this loan loss provision has to be compared to the expected loss according to Basel II and, in the case of a difference, liable equity has to be adjusted. This however assumes that the loan loss provision and the expected loss are based on a similar economic rationale, which is only valid conditionally in current loan loss provisioning methods according to IFRS. Therefore, differences between loan loss provisions and expected losses should only result from different approaches regarding the parameter estimation within each model and not due to different assumptions regarding the outcome of the model. The provisioning and accounting model developed in this paper overcomes the before-mentioned shortcomings and is consistent with an economic rationale of expected losses. Additionally, this model is based on a close-to-market valuation of the loan that is in favor of the basic idea of IFRS. Suggestions for changes in current accounting and capital requirement rules are provided.
\end{abstract}

Keywords: Basel II, expected loss, IFRS, loan loss provision

Manuscript received January 7, 2010, accepted by Christian Schlag (Finance) August 19, 2010.

\section{Introduction}

A loan loss provision (LLP) is currently considered as an adjustment of the book value of a loan which regards future changes in the loan's value due to default events. The expected loss (EL) denotes the expected amount of a loan that will be lost within one year in the case of a default. Furthermore, the Basel II capital requirements demand banks to compare the loan loss provisions with the yearly computed expected losses. Here, it has to be considered that in the case of an excess of the expected loss over the loan loss provision, the shortfall has to be subtracted from the liable equity (Tier $1+$ Tier 2). In case of an excess of the loan loss provision over the expected loss, banks are allowed to add the excess up to $0.6 \%$ of the risk-weighted asset value according to the Internal Ratings-Based Approach to their liable equity (Article 63 (3) Directive 2006/48/EC). Thus, the approach assumes comparability of the expected loss and the loan loss provision in the sense that both quantities follow the same economic rationale and may only differ in the methods to estimate the model-inherent parameters. However, this comparability is not given in three aspects:

First, current accounting rules, e.g., International Financial Reporting Standards (IFRS), postulate that, in general, loans and receivables are measured at their amortized costs. This means the book value of the loan is reduced by repayments and possible provisions using the effective interest method (IFRS 39.09). A loan loss provision can thus be defined as the difference between current book value and present value of expected cash flows (PricewaterhouseCoopers 2002: 152-154). Since the book value just equals the remaining face value, it cannot be considered as a present value of a loan. This holds under the assumption that the loan is classified as "Loans \& Receivables" under IFRS, which is usually the case. The present value of cash flows considers interest payments and discounting. From an economic perspective, the difference between the present value of cash flows under certainty and the present value of expected cash flows under uncertainty is a more 
reasonable economic interpretation of a loan loss provision. Therefore, book values are not useful in computing these provisions.

Second, according to the Capital Requirements Directive the "expected loss,[... ], shall mean the ratio of the amount expected to be lost on an exposure from a potential default of a counterparty or dilution over a one-year period to the amount outstanding at default" (Article 4 (29) Directive 2006/48/EC). There are two shortcomings when comparing this value with loan loss provisions. On the one hand, the expected loss considers a time horizon of one year whereas loan loss provisions consider the whole maturity of the loans. On the other hand, the expected loss only refers to the outstanding amount at default, which equals the residual book value, and does not consider discounting effects. In an economic rationale it is more reasonable to compare total expected losses (TELs) with loan loss provisions, where total expected loss denotes the sum of present values of expected losses over the whole maturity of the loan. It will be formally defined later.

Third, banks are only allowed to create a loan loss provision for a single loan if a credit event has occurred, e.g., the obligor fails to meet the payment schedule. This procedure is counterintuitive since the default risk exists at the loan's initiation and does not arise by occurrence of a credit event. Therefore, one should consider default risk right at the initiation of the loan.

These shortcomings may lead to a distorted capital allocation, e.g., possible under- or overcapitalization with equity due to the lack of comparability of expected losses and loan loss provisions when loans exhibit a maturity of more than one year. Our approach tries to overcome the aforementioned problems by considering present values and by using total expected losses instead of expected losses according to Basel II. Under the assumption of no transaction costs, workout costs, and similar parameters within the computations of loan loss provisions and total expected losses, the loan loss provisions computed according to our method will equal the expected losses of the loan over the whole maturity. Hence, differences between loan loss provisions and total expected losses can only occur by using different parameter estimations or different considerations of costs within each computation. The resulting implications of our approach are a redefinition of the current specific loan loss provision standards and a redefinition of Article 63 (3) Directive 2006/48/EC. Therefore, the main objective is to find an overall solution to unify the divergency existing between expected losses and loan loss provisions. We want to emphasize that both concepts, namely Basel II and IFRS, are consistent on a stand-alone basis regarding their own objectives and assumptions but still exhibit shortcomings when abstracting from a pure accounting or a pure finance point of view. Our paper is organized as follows: After a literature review of the loan loss provision development and possible influences on earnings and capital management in Section 2, our model of a loan loss provision is derived in Section 3. Here, we also show that this loan loss provision equals the total expected loss and so a comparability of these two values is assured. In Section 4, a comparison of our model with current loss provisioning methods according to IFRS with respect to the magnitude in equity capitalization and with respect to the profitand-loss impact is done. Section 5 concludes our results.

\section{Literature Review}

The problem of quantifying uncertain repayments in the context of credits was introduced by $\mathrm{Cy}-$ ert and Trueblood (1957) and Cyert, Davidson, and Thompson (1962). They basically estimated so-called "loss expectancy rates", which can be interpreted as a Loss Given Default (LGD), for which they used probabilities of transition between different age categories of retail debt. This approach was adopted by Kim and Santomero (1993) for bank loans. They developed a Bayesian model to estimate loan loss reserves under the assumption of changing information due to new audits. A comprehensive overview of accounting, determinants and uncertainty of loan loss provisions is given in Beattie, Casson, Dale, McKenzie, Sutcliffe, and Turner (1995). These papers can be regarded as precursors of the concept of expected losses without taking the regulatory point of view into consideration.

Analyses of loan loss provisions provide different and sometimes contradictory results. For example, Liu, Ryan, and Wahlen (1997) showed that the market reacts positively toward loan loss provisions for banks with low regulatory capital, whereas negative reactions were observed for banks with high 
regulatory capital. Furthermore, they observed that increasing loan loss provisions implies higher cash flow predictions since higher loan loss provisions are associated with activities carried out by bank managers to resolve loan default problems (Liu, Ryan, and Wahlen 1997: 145). However, Ahmed, Takeda, and Thomas (1999) refuted the before-mentioned results and showed a significant negative relation between bank stock returns and loan loss provisions (Ahmed, Takeda, and Thomas 1999: 3 et seq.). A summary of several studies regarding the effects of capital management and earnings management on loan loss provisions is provided by Wall and Koch (2000).

Another focus regarding loan loss provisions is the analysis of changes in the provisions due to macroeconomic factors. Laeven and Majnoni (2003) found empirical evidence that banks worldwide delayed provisioning for bad loans even until downturns had already set in. They used balance sheet information for the period 1988 to 1999 for 1,419 banks of 45 countries worldwide. As a result, they found a significant negative relation between GDP growth and relative loan loss provisions. Pérez, Salas, and Saurina (2006) empirically analyzed loan loss provisions in Spain. They used annual data from banks over the period from 1986 to 2002 and examined the relation between loan loss provisions and earnings and capital. Again, the pro-cyclical behavior of loan loss provisions was approved. Another similar investigation was carried out by Quagliariello (2007) for Italian intermediaries using accounting ratios of 207 banks over the period from 1985 to 2002 . He also confirmed the pro-cyclical but delayed behavior of loan loss provisions. Quagliariello (2008) reviewed different empirical analyses about macroeconomic effects on bank stability. The two previous paragraphs describe the difficulties in the interpretation of loan loss provisions and in choosing possible influencing parameters for its estimation.

Regarding the general idea of creating loan loss provisions, Borio and Lowe (2001) were the first who mentioned that there is a discrepancy between the IFRS rules and the Basel II-framework concerning concepts of loss. Benston and Wall (2005) argued that the initial recorded value of a loan in general is underestimated when using historic cost accounting. Additionally, it is argued that "loan loss accounting, therefore, should return to its original function of providing useful informa- tion to investors[... ]" (Benston and Wall 2005: 99). In our opinion, this argument seems to be, at least, doubtful since the primary purpose of a loan loss provision should not be the transmission of information to investors but the risk precaution for the bank.

Another adequate way of creating provisions is the idea of dynamic provisioning. Issues of this type are presented in Mann and Michael (2002) where the general principle of dynamic provisioning is that provisions are in line with an estimate of long-run expected losses (Mann and Michael 2002: 130). In other words, the dynamic provision delays the recognition of the credit risk premium by building up an allowance for expected losses. In case of a no default, the complete allowance, presenting the risk premium, will be dissolved at maturity. Gebhardt (2008) supported the dynamic provisioning and the fair value approach by comparing the current German accounting principles with IFRS, especially according to their weaknesses concerning earnings management.

\section{Loan Loss Provisions and Expected Loss}

\subsection{A Financial Approach}

In this section, we introduce an economic framework for the determination of loan loss provisions of single loans without any consideration of current accounting rules. In general, loan loss provisions should take expected losses of a loan over its lifetime into consideration. Especially in this context, losses occur if a counterparty fails to meet their contractual payment schedule. These losses should contain both repayments and interest payments adjusted by possible cash flows from collaterals. Furthermore, the losses can be considered as a random variable from which expectations can be taken. There are several approaches for pricing risky assets: e.g., the risk-neutral valuation technique known from derivative pricing, the assumption of risk-neutrality of the market participants, or risk-adjusted discount factors like the Capital Asset Pricing Model or the Arbitrage Pricing Theory.

The idea behind the risk-neutral valuation is the computation of an expectation by using so-called risk-neutral probabilities instead of physical probabilities. This approach allows for risk-free dis- 
counting. For determining the risk-neutral probabilities a complete market is assumed, i.e. that every risky cash flow profile can be duplicated at the market. While in reality the assumption of market completeness may not be satisfied perfectly, we nevertheless employ it in our analysis for the sake of simplicity. For an overview of risk-neutral valuation see, e.g., Bingham and Kiesel (2004).

The second approach requires just one assumption, namely that market participants are riskneutral. In this case, the expectation of risky future cash flows is taken with respect to physical probabilities and can also be discounted risk-free. The assumption of risk-neutrality is somehow critical since risk-aversion is a more meaningful constraint for market participants. However, main advantage of the risk-neutral assumption can be found in the ease of exposition of the pricing model.

We will now derive our loan loss provision approach. In an economic rationale, loan loss provisions should equal the expected losses over the whole maturity of the loan. Under consideration of the time value of money it is reasonable to assume:

Assumption 1. The loan loss provision equals the difference between two present values: the value of a risk-free loan and the value of a risky loan.

The value of a risk-free loan equals the present value of promised payments of the contract (i.e. without considering uncertainty) and the value of the risky loan equals the present value of the expected cash flows including uncertainty. This can be formally written as:

$$
\begin{aligned}
\operatorname{LLP}_{t-1}= & \sum_{m=t}^{T} \frac{C F_{m}}{\left(1+r_{t}^{f}\right)^{m-t+1}} \\
& -\mathrm{E}_{Q}\left[\sum_{m=t}^{T} \frac{\widetilde{C F_{m}}}{\left(1+r_{t}^{f}\right)^{m-t+1}}\right],
\end{aligned}
$$

where $\mathrm{E}_{Q}($.$) denotes the risk-neutral expectation,$ $C F_{t}$ denotes the cash flow without uncertainty in time $t$ and equals $C F_{t}=F V_{t-1} \cdot r_{t}^{c}+A_{t}$. Here, $F V_{t}$ denotes the residual face value in $t$ after repayment, $F V_{0}$ denotes the face value of the loan at origin, $A_{t}$ denotes the repayment in time $t, r_{t}^{c}$ denotes the contract interest rate in time $t$ and $r_{t}^{f}$ the risk-free interest rate in time $t$. There is a clear relationship between face value and repayment, namely $F V_{t}=$ $F V_{t-1}-A_{t}$ and $A_{T}=F V_{T-1}$. These relationships describe the development of the residual face value, where it is assumed that the repayment in the final period equals the residual face value of the prior period. Consider for example an amortizable loan with a remaining face value in period $(t-1)$ of 1,000 , a contract interest rate of $5 \%$ and a periodspecific repayment of 100 . The cash flow in period $t$ consists of $50=1,000 \cdot 0,05$ interest and 100 repayment resulting in a cash flow in period $t$ of 150. The remaining face value at the end of period $t$ equals 900. $\widetilde{C F}_{t}$ denotes the cash flow under uncertainty.

We additionally assume:

Assumption 2. The default state is an absorbing state, i.e. once an obligor defaults she cannot recover anymore and the loan ceases to exist.

Therefore, we denote the risk-neutral probability of a default as "write-off probability", $\mathrm{P}_{w o}$, because the loan is written-off by the bank. This default definition is different to the definition of default referred to in current accounting standards and Basel II where a default refers to the occurrence of a so-called "credit event". In these frameworks, default is not an absorbing state. According to the Institut der Wirtschaftsprüfer (IDW), the definition of a credit event with respect to IFRS 39 and Basel II are in general congruent (IDW 2007: 89 et seqq.). We justify this assumption with the fact that there are negligible losses for the bank in the case of a default and a recovery afterwards. We just consider two cases in each period: a usual progress of the loan repayment or an ultimate default, i.e. write-off.

A reduced-form valuation approach for the value of a risky loan can be written as:

$$
\begin{gathered}
\mathrm{E}_{Q}\left[\sum_{t=1}^{T} \frac{\widetilde{C F}_{t}}{\left(1+r_{t}^{f} t^{t}\right.}\right]=\sum_{t=1}^{T} \frac{\left(1-\mathrm{P}_{w o}\right)^{t} \cdot\left(F V_{t-1} \cdot r_{t}^{c}+A_{t}\right)}{\left(1+r_{t}^{f}\right)^{t}} \\
+\sum_{t=1}^{T} \frac{\left(1-\mathrm{P}_{w o}\right)^{t-1} \cdot \mathrm{P}_{w o} \cdot\left(1-\mathrm{LGD}_{t}\right) \cdot F V_{t-1} \cdot\left(1+r_{t}^{c}\right)}{\left(1+r_{t}^{f}\right)^{t}}
\end{gathered}
$$

where $\mathrm{LGD}_{t}$ denotes the relative loss of the amount outstanding and $r_{t}^{c}$ again denotes the contract interest rate in time $t$. We furthermore assume:

Assumption 3. Interest loss is considered by multiplying the LGD with the total amount outstanding including one interest payment, i.e. by multiplying with the factor $F V_{t-1} \cdot\left(1+r_{t}^{c}\right)$. Since we use absorbing states of nature the interest loss is just limited to the next interest payment due and not the cumulated contractual interest. 
For reasons of simplification, we assume that for now $\mathrm{P}_{w o}$ is constant but $\mathrm{LGD}_{t}$ may vary over time. The first sum on the right-hand side in Equation (2) can be interpreted as the expected cash flow in the case of no default and the second sum as the expected cash flow in the case of default. Furthermore, the write-off probabilities for the different time periods are expressed as a product of the marginal survival probabilities of previous time periods and the period-specific write-off probability. If we abstract from the assumption of a constant write-off probability over all periods, the cumulative survival probability for period $t$ will change to $\prod_{k=1}^{t}\left(1-\mathrm{P}_{w o, k}\right)$ and the period-specific write-off probability will rearrange to $\prod_{k=1}^{t-1}\left(1-\mathrm{P}_{w o, k}\right) \cdot \mathrm{P}_{w o, t}$. A further problem will occur when inserting the result from Equation (2) into the second term on the right-hand side in Equation (1). When computing the loan loss provision according to Equation (1), a binomial tree with no absorbing states of nature is implicitly assumed. This, however, is generally incorrect since the existence of an absorbing state always has to be given. Thus, in the case of a default under the given assumptions, all future interests are lost and the creditor only receives a fraction, i.e. (1 - LGD), of one interest payment and the outstanding amount of the loan. Therefore, one has to subtract the sum of all uncollectible future interest payments from the loan loss provision according to Equation (1), i.e. the loan loss provision has to be corrected by the present value of expected future interest payments. To illustrate this idea, consider a loan with maturity of two years, face value equal to 100 , contract interest rate of $10 \%$, a write-off probability of $10 \%$ and a recovery rate of $0 \%$. When abstracting from discounting effects, the value of the loan without uncertainty equals $10+110=120$ and the value of the loan under uncertainty equals $(1-0.1) \cdot 10+(1-0.1)^{2} \cdot 110=$ 98.1. Therefore the uncorrected loan loss provision amounts to $120-98.1=21.9$ but the sum of the present value of the expected losses per period (total expected loss) only amounts to $0.1 \cdot 110+(1-0.1) \cdot 0.1 \cdot 110=20.9$. The difference between uncorrected loan loss provision and total expected loss equals 1 and exactly amounts to the single expected future interest payment which is lost in the case of a default 0.1 10 . Summarizing this part, a correction of the loan loss provision is needed when we assume that the loan can default at any time between initiation and maturity, where default means that the loan ceases to exist (which we refer to as a write-off). Furthermore, we assume that in the case of a default the creditor gets a final payment which amounts to (1 - LGD) times an amount consisting of the outstanding face value plus one additional interest payment.

We will refer to this amount as the correction factor $F$ which is quantified according to Equation (3). The following equation is rearranged to capture the special case $\mathrm{P}_{w o}=1$ by separating the first summand of the second sum. Otherwise, an expression of the form " 0 " would occur, which is not properly defined. For all remaining equations of our approach this separation is omitted for ease of presentation and so $\mathrm{P}_{w o}<1$ must be true.

$$
\begin{aligned}
F_{t-1}=\sum_{m=t}^{T} \frac{\left[1-\left(1-\mathrm{P}_{w o}\right)^{m-t+1}\right] \cdot\left(F V_{m-1} \cdot r_{m}^{c}+A_{m}\right)}{\left(1+r_{m}^{f}\right)^{m-t+1}} \\
-\frac{\mathrm{P}_{w o} \cdot F V_{t-1} \cdot\left(1+r_{t}^{c}\right)}{\left(1+r_{t}^{f}\right)} \\
-\sum_{m=t+1}^{T} \frac{\left(1-\mathrm{P}_{w o}\right)^{m-t} \cdot \mathrm{P}_{w o} \cdot F V_{m-1} \cdot\left(1+r_{m}^{c}\right)}{\left(1+r_{m}^{f}\right)^{m-t+1}} .
\end{aligned}
$$

The following property is proven in Appendix 1.

Lemma 1. The sign of the correction factor $F_{t-1}$ depends on the spread between risk-free interest rate $r^{f}$ and contract interest rate $r^{c}$ of the loan. In case of no spread, $F_{t-1}$ will also be zero.

For the special case $\mathrm{P}_{w o}=0$ the correction factor equals zero. In this case there will be no default risk at all. Therefore, a loan loss provision is not needed and thus no correction factor. Regarding the sign of the correction factor one can assume that in most cases the spread is positive and so is the correction factor. This implies that the uncorrected loan loss provisions (without considering absorbing states and corresponding unconsidered uncollectible future interest payments) are in general too high.

The portion of the initial correction factor, $F_{0}$, on the initial face value of the loan, $F V_{0}$, using three different maturities of two, five and ten years is illustrated in Figure 1. In this figure, we assume constant yearly repayments, a risk-free interest rate of $5 \%$ p.a. and a contract interest rate of $10 \%$. It can be seen that with increasing time to maturity and with increasing write-off probability the influence of the correction factor on the initial face value will also increase. This is especially 
important for loans with a high time to maturity and low creditworthiness.

Now, when subtracting $F_{t-1}$ from $\operatorname{LLP}_{t-1}$ in Equation (1) this finally leads to the corrected loan loss provision LLP $_{c o r, t-1}$ and accordingly to the total expected loss:

$$
\begin{aligned}
& \mathrm{LLP}_{c o r, t-1}=\mathrm{LLP}_{t-1}-F_{t-1}=\mathrm{TEL}_{t-1} \\
& =\sum_{m=t}^{T} \frac{\left(1-\mathrm{P}_{w o}\right)^{m-t} \cdot \mathrm{P}_{w o} \cdot \mathrm{LGD}_{m} \cdot F V_{m-1} \cdot\left(1+r_{m}^{c}\right)}{\left(1+r_{m}^{f}\right)^{m-t+1}} .
\end{aligned}
$$

The generated LLP $\mathrm{Lor}, t-1_{\text {has }}$ to be reduced in the next period in the case of no default in the current period, since the total expected losses decreased. The income statement-related difference of two successive $\mathrm{LLP}_{\text {cor }}$ equals the difference between the corresponding two successive total expected losses. The income statement-related difference which reduces the $L L P_{c o r, t-1}$, denoted as $D P_{t-1, t}$, can be described by:

$$
\begin{aligned}
& D P_{t-1, t}=\frac{\mathrm{P}_{w o} \cdot \mathrm{LGD} \cdot F V_{t-1} \cdot\left(1+r^{c}\right)}{\left(1+r^{f}\right)} \\
& -\sum_{m=t+1}^{T} \frac{\left(1-\mathrm{P}_{w o}\right)^{m-t-1} \cdot \mathrm{P}_{w o} \cdot \mathrm{LGD} \cdot F V_{m-1} \cdot\left(1+r^{c}\right) \cdot\left(\mathrm{P}_{w o}+r^{f}\right)}{\left(1+r^{f}\right)^{m-t+1}},
\end{aligned}
$$

where a flat term structure and a constant LGD are assumed. These assumptions are not needed but are used for ease of exposition.

There are some noticeable characteristics when considering the accounting of the above-mentioned values. The initial accounting value of the loan should equal the present value of the promised payments reduced by the initial LLP ${ }_{c o r, 0}$. Our model distinguishes between the face value and the accounting value of the loan since the market entry

\section{Figure 1: Proportion of the correction} factor

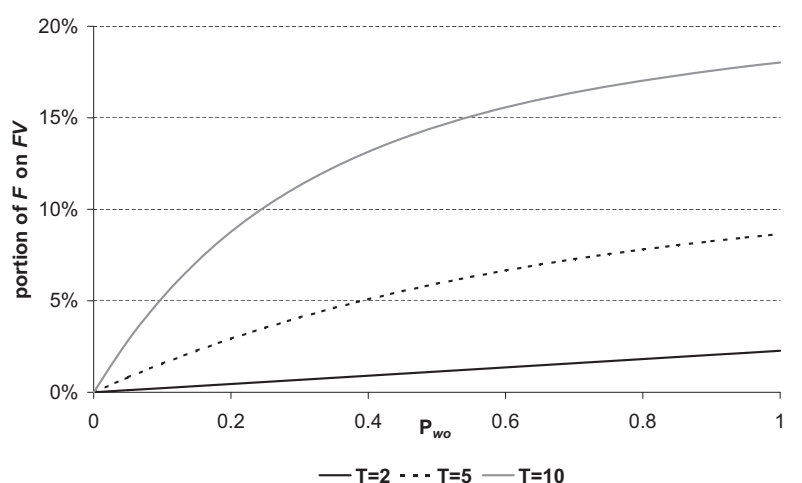

The figure shows the proportion of $F_{0}$ on the face value $F V_{0}$ with respect to the write-off probability, computed according to the example described above. and exit prices are different. Thus, we are in accordance with the opinion of the Joint Working Group of Standard Setters (JWG) (JWG 2001b: 315317). The initial booking of $\operatorname{LLP}_{c o r, 0}$ is recognized in profit or loss as an expense. Any discount or premium of the loan (i.e. difference between present value of the loan and face value) is capitalized and amortized in future periods. The period-specific release of LLP ${ }_{c o r}$ has to be booked as revenue at the end of the survived period. The decrease in the present value of the loan, namely the time effect, is accounted as an expense in the case of an over par-valued loan and as a revenue in the case of an under par-valued loan. The time effect in each period equals the difference between the present value of the loan in the preceding period and the present value of the loan in the current period without consideration of repayments. In case of a par-valued loan there is no time effect and also no discount or premium. In the final period, the present value of the loan equals the outstanding face value. The sum of the period-specific $D P_{t-1, t}$ equals the $\mathrm{LLP}_{c o r, 0}$ generated at the beginning in the case of no default over the whole maturity. When using the effective interest rate method for the amortization of the discount or premium, the expense or revenue offsets the corresponding time effect in each period under the assumption of a flat term structure. In case of no flat term structure, the amounts of amortization and time effect may not offset each other in each period and the resulting difference has to be recognized as an expense or revenue. However, the total of the amortization of the discount or premium and the time effects over the whole maturity remains zero. Thus, losses and gains offset each other in the case of no default over the whole maturity of the loan. If the loan is issued with an agio or disagio (i.e. a difference between face value and amount paid) another premium or discount position has to be capitalized and amortized over the maturity resulting in an expense or a revenue. This premium or discount is independent of the premium or discount which results from under par or over par-valued loans. When abstracting from only two possible states of nature, namely write-off or regular repayment schedule, our general idea of the loan loss provision calculation remains the same. If we, for example, allow for a restructuring of the loan, the valuation of the uncertain payments will change. Three possible states of nature can occur: write-off, 
restructuring and regular repayment schedule which leads to a trinomial tree. Restructuring is in general related to adjusted interest payments, deferred repayments and extended maturities. Once a restructuring is necessary, the obligor can either terminally default or continue her restructured repayment schedule in subsequent periods.

\subsection{Example}

The general procedure for calculating LLP $_{c o r, t-1}$ and the total expected losses is described by using an example of a bullet repayment loan shown in Table 1 . There may be some deviations due to rounding. Here we assume a maturity of four years and a face value of 1,000 , a write-off probability of $6 \%$, and an LGD of $20 \%$. The term structure is assumed to be flat on a level of $5 \%$. The contract interest rate equals $10 \%$.

The cash flow in each period, $C_{t}$, is shown in the first row, repayments are shown in the second row and the interest payment of each period is shown in the third row of Table 1. The uncorrected loan loss provision of each period, $\mathrm{LLP}_{t}$, is presented in the fourth row. The fifth row shows the correction factor for each period, $F_{t}$. Therefore, the corrected loan loss provision $\mathrm{LLP}_{c o r, t}$ equals $\mathrm{TEL}_{t}$ for each period, which is illustrated in the sixth row.

The second part of Table 1 starts with the present value of the promised payments. The eighth row shows the amortization of the premium in each period. The difference between the period-specific present values is denoted as time effect and illustrated in the ninth row. The tenth row shows the period-specific $D P_{t-1, t}$ for the case of no default in the previous periods. The subsequently illustrated total effect equals the sum of the premium amortization, time effect and the $D P_{t-1, t}$ for each period. The last row illustrates the balance sheet valuation of the loan.

Possible accounting records for the different periods are shown in Figure 2. The binomial tree according to this example is shown in Figure 3. The probability of each state of nature and the corresponding payoffs are illustrated. Each end node shows the payoff resulting from this branch.

As a first result, our approach is consistent with an expected loss framework since the particular loan loss provision of each period equals the future total expected losses. Furthermore, our model is consistent with the principle of prudence, especially the imparity principle. This means that possible losses are taken into consideration betimes and revenues are only considered after occurrence. Another example for an amortizable loan is shown in Appendix 2.

\section{Comparison of our Model to IFRS and Basel II}

This section introduces different ways of generating loan loss provisions according to IFRS. Capital market-oriented companies have been obliged to compile their consolidated accounts according to IFRS since the beginning of 2005 (EC 1606/2002, Art. 4). At the same time, capital requirements according to Basel II are also obliged for banks. The Basel II capital requirements were codified by the Directive 2006/49/EC which are obligatory since the beginning of 2007. For a further analysis of the intersection between Basel II and IFRS, we refer to PricewaterhouseCoopers (2006), Cluse, Engels, and Lellmann (2005), Grünberger (2007), and Leitner (2005).

There are, in general, two types of provisions; namely the specific provision and the general provision. Particularly specific provisions can be regarded as direct corrections in value of a single loan - general provisions can be defined more broadly. Group impairment is recognized whenever observable data show a measurable decrease in estimated future cash flows that cannot yet be assigned to individual loans.

The first possibility for a loan loss provision according to IFRS is the specific provision. It is created only after the occurrence of an impairment trigger event for single financial assets. An impairment trigger event is another denotation for a credit event used in the IFRS context. We will refer to the denotation 'credit event' in the upcoming parts of the paper. Impairment trigger events are, according to IFRS 39.59, events like significant financial difficulties of the issuer or obligor, or a breach of contract, such as a default or delinquency in interest or principal payments. The amount of the specific provision equals the "[. . . ] difference between the asset's carrying amount and the present value of estimated future cash flows (excluding future credit losses that have not been incurred) discounted at the financial asset's original effective interest rate [.. . ]", where "carrying amount" refers to the book value of the asset (IFRS 39.63). 
BuR - Business Research

Official Open Access Journal of VHB

Verband der Hochschullehrer für Betriebswirtschaft e.V.

Volume 3 | Issue 2 | November 2010 | 133-149

Table 1: Example of a loan loss provision computation

\begin{tabular}{|c|c|c|c|c|c|}
\hline $\mathbf{t}$ & 0 & 1 & 2 & 3 & 4 \\
\hline$C_{t}$ & $-1,000.00$ & 100.00 & 100.00 & 100.00 & $1,100.00$ \\
\hline Repayment & -- & 0.00 & 0.00 & 0.00 & $1,000.00$ \\
\hline Interest payments & -- & 100.00 & 100.00 & 100.00 & 100.00 \\
\hline 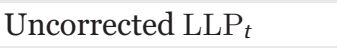 & 57.64 & 41.65 & 26.55 & 12.57 & 0.00 \\
\hline$F_{t}$ & 14.72 & 7.75 & 2.72 & 0.00 & -- \\
\hline $\mathrm{LLP}_{c o r, t} / \mathrm{TEL}_{t}$ & 42.92 & 33.90 & 23.83 & 12.57 & 0.00 \\
\hline Present value & $1,177.30$ & $1,136.16$ & $1,092.97$ & $1,047.62$ & $1,000.00$ \\
\hline Premium amortization & -- & 41.14 & 43.19 & 45.35 & 47.62 \\
\hline Time effect & -- & -41.14 & -43.19 & -45.35 & -47.62 \\
\hline$D P_{t-1, t}$ & -- & 9.02 & 10.08 & 11.25 & 12.57 \\
\hline Total effect & -42.92 & 9.02 & 10.08 & 11.25 & 12.57 \\
\hline Balance sheet valuation & $1,134.38$ & $1,102.26$ & $1,069.14$ & $1,035.05$ & 0.00 \\
\hline
\end{tabular}

The table shows a bullet repayment loan with a maturity of four years and a face value of 1,000. We assume a risk-free interest rate of $5 \%$ p.a., a contract interest rate of $10 \%$ p.a., a write-off probability of $6 \%$, and an LGD of $20 \%$.

Although the usage of the fair value is often proclaimed by different institutions (e.g., the Joint Working Group of Standard Setters), a descriptive approach for obtaining a fair value is not given (JWG 2001a: 28). For example, possible future credit losses have to be excluded in the fair value computation (IFRS 39.63). However, market participants anticipate future interest payments as well as the point in time of these interest payments and, of course, possible future losses. In the case of no constant effective interest rate during the maturity, the values discounted with the initial effective interest rate are hardly economically interpretable. Therefore, the so-called fair value according to IFRS is less market-oriented than our approach and we do not suffer from a higher calculation effort since all relevant parameters have to be estimated according to Basel II anyway. The specific loan loss provision according to IFRS would amount to 38.51 ( = face value - present value of expected cash flows discounted with the effective interest rate)

$$
\begin{array}{cc} 
& 38.51=1,000-\sum_{t=1}^{4} \frac{(1-0.06)^{t} \cdot 100}{1.1^{t}} \\
- & \sum_{t=1}^{4} \frac{(1-0.06)^{t-1} \cdot 0.06 \cdot(1-0.2) \cdot(1,000+100)}{1.1^{t}} \\
+ & \frac{(1-0.06)^{4} \cdot 1,000}{1.1^{4}}
\end{array}
$$

when referring to our example described in Section 3.2.

Another possibility for creating a loan loss provision according to IFRS is the general provision, which is created only for loan portfolios that were not subject to a specific provision where the portfolio consists of loans with similar features - for example branch or collateralization (IFRS 39.64). Here, we can differentiate as to whether a credit event already took place or not.

The default probability is equal to one in the case of an already occurred credit event. The general loan loss provision $\operatorname{LLP}_{g}^{d}$ is computed by the following equation:

$$
\operatorname{LLP}_{g}^{d}=\sum_{i=1}^{m} \mathrm{EAD}_{i} \cdot \overline{\mathrm{LGD}}
$$

where $\mathrm{EAD}_{i}$ denotes the exposure at default of loan $i$ and $\overline{\text { LGD }}$ denotes the average Loss Given Default of the portfolio. Here it is implicitly assumed that a loan cannot recover once a default occurs. As a result, the default probability is assumed to equal the write-off probability and a default event is treated as a write-off event - which is not in line with the definitions of a default stated in IFRS. As stated in IFRS 39.65, the possibility of reorganization is given and so a reduction of the loan loss provision is demanded. If one assumes that default is an absorbing state of nature, IFRS 39.65 seems to be obsolete. The single summands within $\mathrm{LLP}_{g}^{d}$ for a loan portfolio consisting of equal loans according to the example of Section 3.2 would amount to 200 (= face value LGD).

In case of nonexistence of a credit event the general loan loss provision, denoted by $\operatorname{LLP}_{g}^{n d}$, is created 
BuR - Business Research

Official Open Access Journal of VHB

Verband der Hochschullehrer für Betriebswirtschaft e.V.

Volume 3 | Issue 2 | November 2010 | 133-149

\section{Figure 2: Possible accounting records for the example presented in Table 1}

Accounting records:

\begin{tabular}{|c|c|c|c|c|c|}
\hline \multirow[t]{3}{*}{$t=0:$} & Loans and Receivables & $1,177.30$ & to & Cash & $1,000.00$ \\
\hline & Loan Loss Provision & 42.92 & & Loans and Receivables & 42.92 \\
\hline & & & & Premium & 177.30 \\
\hline \multirow[t]{4}{*}{$t=1:$} & Cash & 100.00 & to & Interest Revenues & 141.14 \\
\hline & Premium & 41.14 & & & \\
\hline & Loans and Receivables & 9.02 & to & Revenues from $D P_{t-1, t}$ & 9.02 \\
\hline & Expenses & 41.14 & & Loans and Receivables & 41.14 \\
\hline \multirow[t]{5}{*}{$t=4:$} & Cash & 100.00 & to & Interest Revenue & 147.62 \\
\hline & Premium & 47.62 & & & \\
\hline & Loans and Receivables & 12.57 & to & Revenues from $D P_{t-1, t}$ & 12.5 \\
\hline & Expenses & 47.62 & & Loans and Receivables & 47.62 \\
\hline & Cash & $1,000.00$ & to & Loans and Receivables & $1,000.0$ \\
\hline
\end{tabular}

The figure shows possible corresponding accounting records for the example of a loan loss provision according to Table 1.

and can be computed by the following equation:

$$
\mathrm{LLP}_{g}^{n d}=\sum_{i=1}^{m} \mathrm{EAD}_{i} \cdot \overline{\mathrm{PD}} \cdot \overline{\mathrm{LGD}} \cdot \overline{\mathrm{LIP}}
$$

where $\overline{\mathrm{PD}}$ denotes the average default probability of the portfolio and $\overline{\mathrm{LIP}}$ denotes the average Loss Identification Period (LIP) (PricewaterhouseCoopers 2006: 36, Figure 1). The LIP is a fractional value of the number of months between the appearance of the default event and its recognition by the bank over twelve months - it can be interpreted as a time adjustment of the default probability. However, an $\overline{\mathrm{LIP}}$ between zero and one reduces the $\mathrm{LLP}_{g}^{\text {nd }}$ and possible expected losses, which may be already incurred, are not considered when creating the loan loss provision. During the time span of occurrence and recognition, capital is misallocated due to an underestimated amount of the loan loss provision. Thus, the imparity principle is partially reversed by using this adjustment. The single summands within $\mathrm{LLP}_{g}^{n d}$ for a loan portfolio consisting of equal loans according to the example of Section 3.2 would amount to 12 (= face value $\cdot$ LGD $\cdot$ PD) assuming an LIP equal to one.

Due to the definition of the default probability, the general provision just refers to one year (Article 4 (25) Directive 2006/48/EC). This is not in line with a reasonable economic interpretation of a loan loss provision since the principle of prudence and the imparity principle are only partially allowed for due to the shortened time horizon of the probability of default and so the true expected losses are just partially considered.

Now we compare the expected-loss concept of Basel II with our provisioning approach described in Section 3.1 and afterwards with the provisioning rules according to IFRS. According to Basel II, loan loss provisions have to be compared to the amount of the expected loss (Article 63 (3) Directive 2006/48/EC). Our loan loss provision approach in Equation (4) differs from the expected loss described in Basel II in three ways: First, we use cumulated write-off probabilities instead of probabilities of default. However, there should be a functional relationship between these two values and for single periods the default probability is an upper bound for the write-off probability. Second, we consider the sum of the expected losses in contrast to one-year expected losses as proclaimed in Basel II. A comparison between loan loss provisions and expected losses is not favorable in our understanding. Third, the payment structure over different time periods is considered by discounting. 


\section{Figure 3: Binomial tree for the bullet repayment loan example}

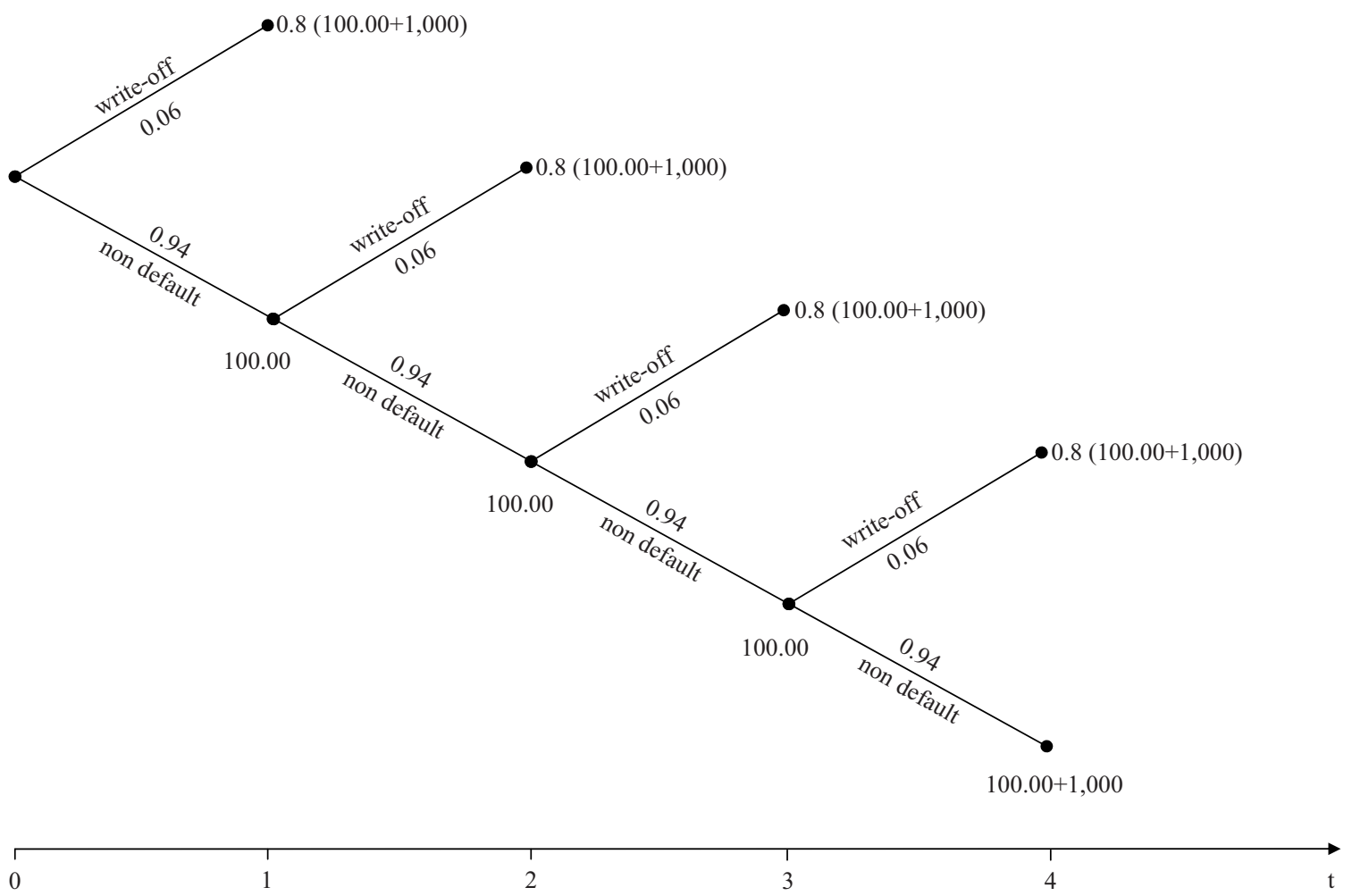

This figure shows the binomial tree according to the example of the bullet repayment loan. Each branch is denoted with the state of nature and the corresponding probability of occurrence. Furthermore the payoffs for each state are also presented.

When comparing the expected-loss concept with the specific loan loss provision according to IFRS the first discrepancy concerns the time horizon of the expected losses, which is just one year in the Basel II framework (Article 4 (29) Directive 2006/48/EC). Furthermore, expected losses, which also include losses that are not incurred, are considered in Basel II but are not allowed to be considered under IFRS. Additionally, the specific loan loss provision can only be created after occurrence of a credit event. In contrast to this, Basel II requires that in the case of a credit event the probability of default equals one for the computation of the expected loss. Thus, according to Basel II it is assumed that in this case the probability of reorganization is zero and the loan will be written off. Therefore, it is obvious that there is a difference in interpretation of the specific provisions and the expected loss according to Basel II due to different regulatory assumptions.

Regarding the general provision with occurrence of a credit event, $\operatorname{LLP}_{g}^{d}$ is equal to the expected portfolio loss when assuming an EAD-weighted average Loss Given Default. In case of no credit event, the amount of $\operatorname{LLP}_{g}^{n d}$ equals the expected portfolio loss according to Basel II if LIP equals one and the average probability of default and the average Loss Given Default are EAD-weighted. Summarizing this section, it can be seen that all types of provisions in the framework of IFRS hardly comply with a reasonable economic definition of an expected loss, i.e. considering the cumulative expected loss over the whole maturity. In contrast to this, our model has the advantage of considering the total expected loss of a loan. However, a discrepancy between Basel II and our approach is given since we use total expected losses and Basel II only uses yearly expected losses. It seems at least doubtful to treat the expected loss as period specific and not as a period-independent total expected loss. It is also doubtful that expected losses are not considered until a credit event occurs re- 
garding the specific loan loss provision under IFRS. Here, it is implicitly assumed that no losses are expected at loan initiation - this does not comply with both the principle of prudence and a general economic rationale.

Provision-specific impacts affect the income statement when using the different types of loan loss provisions. These impacts can be the creation and reduction of the loan loss provision, the amortization of possible discounts or premiums, and effects resulting from changes in the present value over time. Generally, our approach and the specific provision according to IFRS pursue a rather strong imparity principle since the expected losses over the whole maturity are considered in the loan loss provision. For the specific provision, this only holds in the case of a credit event, whereas the consideration in our approach is independent whether a credit event occurred or not because expected losses are always considered at initiation of the loan.

The general provision without the occurrence of a credit event only rectifies yearly expected losses of the actual exposure. Only the difference of consecutive yearly expected losses is income-statementrelated after the initial creation of a loan loss provision. The upward revaluation of the loan amounting to the expected loss of the final period leads to a revenue at maturity in the case of no default. If a credit event occurs, the provision development is similar to one without a credit event. However, a write-off is taken as certain, i.e. the probability of default equals one at provision initiation which will result in higher absolute amounts.

The developments for all cases referring to our example in Section 3.2 are shown in Figure 4. We present the relative influence to the initial face value of the loan for the different provision alternatives on the profit-and-loss accounting (P\&L). We assume that the loan will not be written-off over the whole maturity. The relative impacts of our model, the specific provision, and the general provision without credit event refer to the left axis. The relative impact of the general provision with credit event refers to the right axis since the probability of default equals one and therefore the scale of the impact is higher. For cases of specific provisions and the general provision with credit event according to IFRS, we assume that the credit event already occurred at the initiation of the loan. This is not an unusual practice since, e.g., in Ger- many obligors exhibiting an entry in the "black list" of the "Schutzgemeinschaft für allgemeine Kreditsicherung" (kind of an association for the protection of loan covering) is treated as a credit event and thus these obligors are considered as defaulted at loan initiation (compare IFRS 39.59 (a)).

\section{Figure 4: Relative profit-and-loss $(P \& L)$ impact of different loan loss provisions}

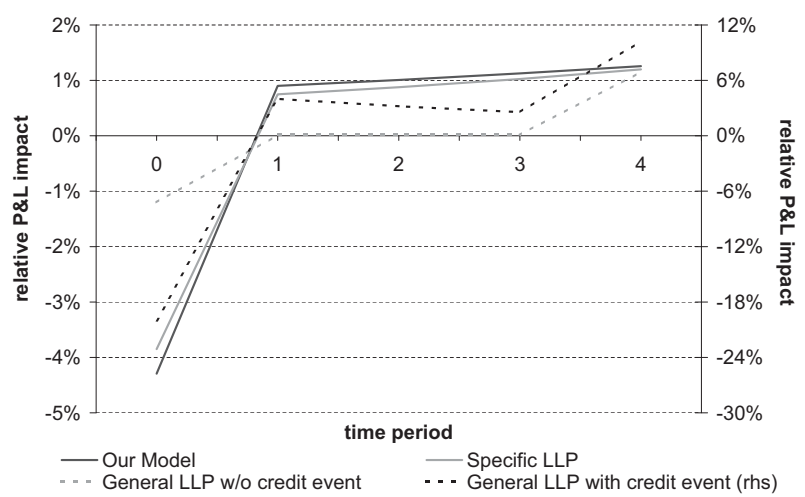

The figure shows the development of the relative profit-andloss impact, i.e. the portion of the earnings and expenses related to the initial face value, based on the example given in Section 3.2. Here, the developments according to the alternative provisioning methods affecting the profit and loss are shown. The illustration of the general loan loss provision with credit event refers to the right axis (rhs) since the relative amount is much higher than for the others.

It can be seen from Figure 4 that there are two different types of developments: There is an initial expense which is compensated by revenues that are similarly distributed over the following periods when regarding the specific loan loss provision according to IFRS and our loss provisioning approach. The two general provision methods reveal a different development - with an initial expense, a relative small release amount in the following periods and a high remaining release at maturity. However, all earnings and expenses offset each other for every kind of provisioning method in the case of no default over the total maturity.

In comparison to the general provisions, our model allows for the cumulative expected loss over the whole maturity whereas the general provisions only consider the yearly expected losses. It also has to be considered that our model uses writeoff probabilities instead of default probabilities. Therefore, the impact on the P\&L-accounting of the IFRS-based provisions is higher since the default probability is greater or equal to the write-off 
probability. The relative P\&L impact of the different loss provisioning methods for the amortizable loan, presented in Appendix 2, is shown in Appendix 3.

If we translate our idea of total expected losses to the capital requirements according to Basel II there will be no need for a change in liable equity due to the equality of total expected loss and loan loss provision. Nevertheless, under the current Basel II-regulations our computed loan loss provision amount differs from the expected loss and so an adjustment in liable equity is needed. When referring to the specific provision with occurrence of a credit event according to IFRS an unnecessary capital increase will result. This holds because the expected loss according to Basel II then equals the product of LGD and EAD, which is usually higher than the specific provision under IFRS. Therefore, an insufficient amount is taken for provisioning and so the liable capital has to be increased. In the case of nonexistence of a credit event no specific provision is created under IFRS but an expected loss according to Basel II is still at hand. Additional capital has to be added to the liable equity as well. There is no distortion in capital when applying the general provisions with credit event and without credit event and a Loss Identification Period equal to one. It is assumed for the general provision with credit event that the complete portfolio is writtenoff since the default probability equals one. This assumption is at least doubtful. For the general provision without credit event and Loss Identification Period equal to one, the capital allocation only considers one year and not the whole maturity. The question arises whether these approaches comply with an economic rationale of risk management. In each case there is no adequate capital allocation in the sense of a consideration of the total expected losses. Either the capital allocation is too high or too low.

For illustrative purposes we refer to our example of a bullet repayment loan described in Section 3.2. The total expected loss over the whole maturity of the loan results in 42.92 and equals our loan loss provision. In case of a credit event, a specific provision according to IFRS has to be created and amounts, as mentioned above, to 38.51. According to Basel II the probability of default equals one and so the expected loss under Basel II equals 200. About 160 monetary units have to be added to the liable equity under the current accounting and regulating legislation, where this amount is almost four times higher than the initial total expected loss of the loan. In the case that no credit event takes place, no specific loan loss provision is needed under IFRS, but the expected loss under the Basel II regime amounts to 12. Again, additional capital has to be raised but this time only about a quarter of the initial total expected loss.

\section{Conclusion}

The aim of this paper was to develop a loan loss provision model that complies with an economic rationale of expected losses. In this context, we intentionally deviated from the definition of expected loss according to Basel II since it seems reasonable that the expected loss should cover possible losses over the remaining maturity of a loan. Although the specific provision refers to the remaining maturity, there are some difficulties in comparing the frameworks (Basel II vs. IFRS) in handling credit events and related risk covering.

We use write-off probabilities instead of default probabilities in our model but a functional relationship between these two measures should exist. Additionally, we introduce a correction factor and show that the sign of this factor depends on the spread between risk-free interest rate and contract interest rate. Even when using default probabilities, an absorbing state, i.e. a state in which the loan definitely defaults without the possibility of recovering, should always exist in every period. Thus, a correction factor is generally needed for loan loss provisions that are calculated as a difference between promised and expected payments. However, this fact was neither allowed for in the literature nor in the current accounting rules. This negligence may lead to capital distortions.

Our approach incorporates the cumulated expected losses at the beginning of the loan's maturity. In the case of no default in subsequent periods, the loan loss provision is partly reversed in each period. Our model offers a higher transparency since the loan loss provision in each period exactly equals the sum of expected losses. Furthermore, the pro-cyclical effect of the loan loss provision in an economic downturn is reduced by using this prospective approach due to the initial consideration of expected losses - not only in the case of a credit event. For example, a downturn may lead to higher write-off frequencies and higher LGDs, which in our case 
result in an adjustment of the existing loan loss provisions. Under the IFRS regime, however, a downturn may lead to higher default frequencies and therefore more loans will probably suffer a credit event that will eventually lead to the creation of loan loss provisions. This process results in a higher burden for the banks than our approach. Additionally, the expected loss according to Basel II is overestimated in the case of higher credit event frequencies since the default probability is assumed to be one. Thus, additional liable equity has to be added, which in turn may result in a liquidity shortage amplifying the default frequency. This causal relationship was also recognized by the IASB and presented at the Pittsburgh G20 Summit 2009.

A general question arises referring to necessary changes in accounting and capital requirement rules. First, regarding the accounting rules, a change from discounting by the initial effective interest rate to a risk-free rate is appropriate. Regarding the creation of general provisions, the correct time horizon of a loan should be the total maturity. In general, a loan loss provision should be created foresighted and not after occurrence of a credit event to account for the prudence and imparity principle. Second, regarding the capital requirement rules, a time horizon of one year seems to be too short-dated for an adequate credit risk coverage. Therefore, the both frameworks IFRS and Basel II, which of course are consistent on a stand-alone basis, should be converged to provide a holistic approach that consistently treats the interrelation between expected losses and loan loss provisions. Our approach could contribute consistency between both frameworks for not comparing apples and oranges although they are both fruits. 


\section{Appendix 1}

Proof.

(A1)

$$
\begin{aligned}
F_{t-1}= & \sum_{m=t}^{T} \frac{\left[1-\left(1-\mathrm{P}_{w o}\right)^{m-t+1}\right] \cdot\left(F V_{m-1} \cdot r_{m}^{c}+A_{m}\right)}{\left(1+r_{m}^{f}\right)^{m-t+1}} \\
& -\sum_{m=t}^{T} \frac{\left(1-\mathrm{P}_{w o}\right)^{m-t} \cdot \mathrm{P}_{w o} \cdot F V_{m-1} \cdot\left(1+r_{m}^{c}\right)}{\left(1+r_{m}^{f}\right)^{m-t+1}} \\
= & \sum_{m=t}^{T} \frac{F V_{m-1} \cdot r_{m}^{c}}{\left(1+r_{m}^{f}\right)^{m-t+1}}-\sum_{m=t}^{T} \frac{\left(1-\mathrm{P}_{w o}\right)^{m-t} \cdot F V_{m-1} \cdot r_{m}^{c}}{\left(1+r_{m}^{f}\right)^{m-t+1}}+\sum_{m=t}^{T} \frac{A_{m}}{\left(1+r_{m}^{f}\right)^{m-t+1}} \\
& -\sum_{m=t}^{T} \frac{\left(1-\mathrm{P}_{w o}\right)^{m-t} \cdot\left(1-\mathrm{P}_{w o}\right) \cdot A_{m}}{\left(1+r_{m}^{f}\right)^{m-t+1}}-\sum_{m=t}^{T} \frac{\left(1-\mathrm{P}_{w o}\right)^{m-t} \cdot \mathrm{P}_{w o} \cdot F V_{m-1}}{\left(1+r_{m}^{f}\right)^{m-t+1}}
\end{aligned}
$$

We use the constraint $A_{m}=F V_{m-1}-F V_{m}$ and rearrangements:

(A2)

$$
\begin{aligned}
= & \sum_{m=t}^{T} \frac{F V_{m-1} \cdot\left(1+r_{m}^{c}\right)}{\left(1+r_{m}^{f}\right)^{m-t+1}}-\sum_{m=t}^{T} \frac{\left(1-\mathrm{P}_{w o}\right)^{m-t} \cdot F V_{m-1} \cdot\left(1+r_{m}^{c}\right)}{\left(1+r_{m}^{f}\right)^{m-t+1}}-\sum_{m=t}^{T} \frac{F V_{m}}{\left(1+r_{m}^{f}\right)^{m-t+1}} \\
& +\sum_{m=t}^{T} \frac{\left(1-\mathrm{P}_{w o}\right)^{m-t} \cdot F V_{m}}{\left(1+r_{m}^{f}\right)^{m-t+1}}-\sum_{m=t}^{T} \frac{\left(1-\mathrm{P}_{w o}\right)^{m-t} \cdot \mathrm{P}_{w o} \cdot F V_{m}}{\left(1+r_{m}^{f}\right)^{m-t+1}}
\end{aligned}
$$

Now, we denote $x_{t}$ as the spread in period $t$. Therefore, it holds: $r_{t}^{c}=r_{t}^{f}+x_{t}$

$$
\begin{aligned}
=\quad \sum_{m=t}^{T} \frac{F V_{m-1} \cdot\left(1+r_{m}^{f}+x_{m}\right)}{\left(1+r_{m}^{f}\right)^{m-t+1}}-\sum_{m=t}^{T} \frac{\left(1-\mathrm{P}_{w o}\right)^{m-t} \cdot F V_{m-1} \cdot\left(1+r_{m}^{f}+x_{m}\right)}{\left(1+r_{m}^{f}\right)^{m-t+1}} \\
\quad-\sum_{m=t}^{T} \frac{F V_{m}}{\left(1+r_{m}^{f}\right)^{m-t+1}}+\sum_{m=t}^{T} \frac{\left(1-\mathrm{P}_{w o}\right)^{m-t} \cdot F V_{m}}{\left(1+r_{m}^{f}\right)^{m-t+1}}-\sum_{m=t}^{T} \frac{\left(1-\mathrm{P}_{w o}\right)^{m-t} \cdot \mathrm{P}_{w o} \cdot F V_{m}}{\left(1+r_{m}^{f}\right)^{m-t+1}} \\
F V_{\underline{T}=0} \quad F V_{t-1}-\sum_{m=t}^{T} \frac{\left(1-\mathrm{P}_{w o}\right)^{m-t} \cdot \mathrm{P}_{w o} \cdot F V_{m}}{\left(1+r_{m}^{f}\right)^{m-t+1}}-F V_{t-1}+\sum_{m=t}^{T} \frac{\left(1-\mathrm{P}_{w o}\right)^{m-t} \cdot \mathrm{P}_{w o} \cdot F V_{m}}{\left(1+r_{m}^{f}\right)^{m-t+1}} \\
+\sum_{m=t}^{T} \frac{\left(1-\left(1-\mathrm{P}_{w o}\right)^{m-t}\right) \cdot F V_{m-1} \cdot x_{m}}{\left(1+r_{m}^{f}\right)^{m-t+1}}=\sum_{m=t}^{T} \frac{\left(1-\left(1-\mathrm{P}_{w o}\right)^{m-t}\right) \cdot F V_{m-1} \cdot x_{m}}{\left(1+r_{m}^{f}\right)^{m-t+1}}
\end{aligned}
$$

Here, it can be seen that the sign of $F$ depends on the $x_{t}$-weighted sum of the present values. The sign of the correction factor solely depends on the sign of $x$ in the case of a constant $x_{t}$ for all periods. 


\section{Appendix 2}

Table 2: Example of a loan loss provision computation for an amortizable loan

\begin{tabular}{|c|c|c|c|c|c|}
\hline $\mathbf{t}$ & 0 & 1 & 2 & 3 & 4 \\
\hline$C_{t}$ & $-1,000.00$ & 350.00 & 325.00 & 300.00 & 275.00 \\
\hline Repayment & -- & 250.00 & 250.00 & 250.00 & 250.00 \\
\hline Interest payments & -- & 100.00 & 75.00 & 50.00 & 25.00 \\
\hline 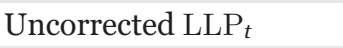 & 34.60 & 20.19 & 9.78 & 3.14 & 0.00 \\
\hline$F_{t}$ & 6.30 & 2.62 & 0.68 & 0.00 & -- \\
\hline $\mathrm{LLP}_{c o r, t} / \mathrm{TEL}_{t}$ & 28.30 & 17.57 & 9.10 & 3.14 & 0.00 \\
\hline Present value & $1,113.51$ & 819.19 & 535.15 & 261.90 & 250.00 \\
\hline Premium amortization & -- & 44.32 & 34.04 & 23.24 & 11.90 \\
\hline Time effect & -- & -44.32 & -34.04 & -23.24 & -11.90 \\
\hline$D P_{t-1, t}$ & -- & 10.73 & 8.48 & 5.96 & 3.14 \\
\hline Total effect & -28.30 & 10.73 & 8.48 & 5.96 & 3.14 \\
\hline Balance sheet valuation & $1,085.21$ & 801.61 & 526.05 & 258.76 & 0.00 \\
\hline
\end{tabular}

The table shows an amortizable loan with a maturity of four years and a face value of 1,000. Furthermore, we assume a risk-free interest rate of $5 \%$ p.a., a contract interest rate of $10 \%$ p.a., a write-off probability of $6 \%$, and an LGD of $20 \%$.

Figure 5: Accounting records for the example presented in Table 2

Accounting records:

\begin{tabular}{|c|c|c|c|c|c|}
\hline$t=0:$ & Loans and Receivables & $1,113.51$ & to & Cash & $1,000.00$ \\
\hline & Loan Loss Provision & 28.30 & & Loans and Receivables & 28.30 \\
\hline & & & & Premium & 113.51 \\
\hline$t=1:$ & Cash & 350.00 & to & Interest Revenues & 144.32 \\
\hline & Premium & 44.32 & & Loans and Receivables & 250.00 \\
\hline & Loans and Receivables & 10.73 & to & Revenues from $D P_{t-1, t}$ & 10.73 \\
\hline & Expenses & 44.32 & & Loans and Receivables & 44.32 \\
\hline$t=4:$ & Cash & 275.00 & to & Interest Revenue & 36.90 \\
\hline & Premium & 11.90 & & Loans and Receivables & 250.00 \\
\hline & Loans and Receivables & 3.14 & to & Revenues from $D P_{t-1, t}$ & 3.14 \\
\hline & Expenses & 11.90 & & Loans and Receivables & 11.9 \\
\hline
\end{tabular}

The figure shows the corresponding accounting records for the example of a loan loss provision according to Table 2. 


\section{Appendix 3}

\section{Figure 6: Relative profit-and-loss $(P \& L)$ impact of different loan loss provisions}

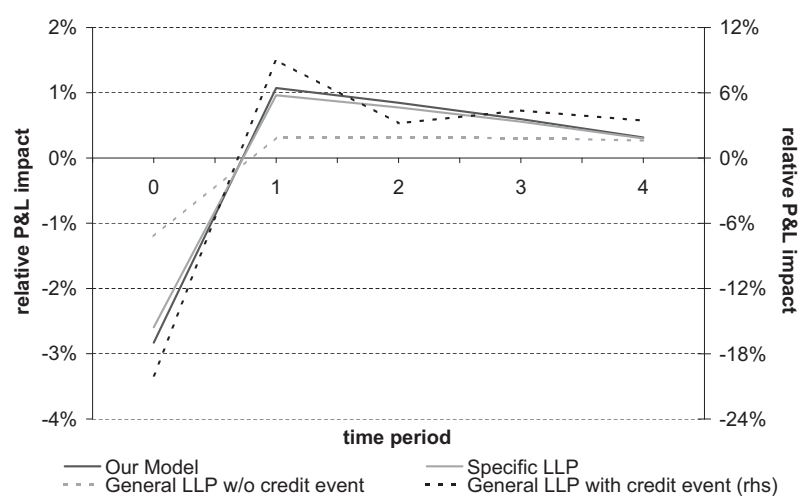

The figure shows the development of the relative profit-andloss impact based on the example given in the Appendix 2. Here, the development according to the alternative provisioning methods affecting the profit and loss is shown. The illustration of the general loan loss provision with credit event refers to the right axis (rhs) since the relative amount is much higher than for the others.

\section{Acknowledgement}

We thank the participants of the Business Research Conference "Finance, Accounting \& Taxation" 2009 in Frankfurt/Oder for the discussion. We are furthermore very grateful for the suggestions made by two anonymous referees and the Department Editor Christian Schlag which definitely increased the quality of the paper. We are also grateful for helpful comments from Peter Reichling.

\section{References}

Ahmed, Anwer S., Carolyn Takeda, and Shawn Thomas (1999): Bank Loan Loss Provisions: A Reexamination of Capital Management, Earnings Management and Signaling Effects, Journal of Accounting and Economics, 28 (1): 1-25.

Beattie, Vivien A., Peter D. Casson, Richard S. Dale, George W. McKenzie, Charles M. S. Sutcliffe, and Michael J. Turner (1995): Banks and Bad Debts: Accounting for Loan Losses in International Banking, 1st ed., Wiley: Chichester.

Benston, George J. and Larry D. Wall (2005): How Should Banks Account for Loan Losses, Journal of Accounting and Public Policy, 24 (2): 81-100.

Bingham, Nicholas H. and Rüdiger Kiesel (2004): Risk-Neutral Valuation: Pricing and Hedging of Financial Derivatives, 2nd ed., Springer: New York.

Borio, Claudio and Philip Lowe (2001): To Provision or Not to Provision, BIS Quarterly Review, September: 36-48.

Cluse, Michael, Jörg Engels, and Peter Lellmann (2005): Die Behandlung von Kreditrisiken unter Basel II und IAS 39, Deloitte White Paper No. 19.
Cyert, Richard M., H. Justin Davidson, and Gerald L. Thompson (1962): Estimation of the Allowance for Doubtful Accounts by Markov Chains, Management Science, 8 (3): 287-303.

Cyert, Richard M. and Robert M. Trueblood (1957): Statistical Sampling Techniques in the Aging of Accounts Receivable in a Department Store, Management Science, 3 (2): 185-195.

Gebhardt, Günther (2008): Accounting for Credit Risk: Are the Rules Setting the Right Incentives?, International Journal of Financial Services Management, 3 (1): 24-44.

Grünberger, David (2007): Basel II: Schnittstellen und Berechnung auf Basis der IFRS, Kapitalmarktorientierte Rechnungslegung, 7 (5): 274-285.

IASB (2006): Fair Value Measurements, Part 2: SFAS 157 Fair Value Measurements, Discussion Paper, http://www.naic.org/documents/committees_ex_isftf_isawg_ DDFairValue2.pdf (Access date: 2010-08-23).

IDW (2007): IDW RS HFA 9: Abgang von finanziellen Vermögenswerten nach IAS 39, Official Statement, Institut der Wirtschaftsprüfer.

JWG (2001a): Financial Instruments and Similar Items, Discussion Paper, Joint Working Group of Standard Setters, http://www.iasplus.com/resource/fijwg-1.pdf (Access date: 2010-08-24).

JWG (2001b): Financial Instruments and Similar Items: Application Supplement, Discussion Paper, Joint Working Group of Standard Setters, http://www.iasplus.com/resource/fijwg2.pdf (Access date: 2010-08-24).

Kim, Daesik and Anthony M. Santomero (1993): Forecasting Required Loan Loss Reserves, Journal of Economics and Business, 45 (3-4): 315-329.

Laeven, Luc and Giovanni Majnoni (2003): Loan Loss Provisioning and Economic Slowdowns: Too Much, Too Late?, Journal of Financial Intermediation, 12 (2): 178-197.

Leitner, Frank (2005): Basel II-Parameter im IASWertberichtigungsprozess, Kapitalmarktorientierte Rechnungslegung, 5 (4): 165-170.

Liu, Chi-Chun, Stephen G. Ryan, and James M. Wahlen (1997): Differential Valuation Implications of Loan Loss Provisions Across Banks and Fiscal Quarters, Accounting Review, 72 (1): 133-146.

Mann, Fiona and Ian Michael (2002): Dynamic Provisioning: Issues and Application, Financial Stability Review, 13: 128136.

Pérez, Daniel, Vincente Salas, and Jesús Saurina (2006): Earnings and Capital Management in Alternative Loan Loss Provision Regulatory Regimes, Working Paper, Banco de España, http://www.bde.es/webbde/Secciones/Publicaciones/Publica cionesSeriadas/DocumentosTrabajo/o6/Fic/dto614e.pdf (Access date: 2010-08-24).

PricewaterhouseCoopers (2002): IAS für Banken, 2nd ed., Fachverlag Moderne Wirtschaft: Frankfurt am Main.

PricewaterhouseCoopers (2006): IFRS und Basel II Eine Schnittstellenanalyse, 2nd ed., Fachverlag Moderne Wirtschaft: Frankfurt am Main.

Quagliariello, Mario (2007): Bank's Riskiness Over the Business Cycle: A Panel Analysis on Italian Intermediaries, Applied Financial Economics, 17 (2): 119-138.

Quagliariello, Mario (2008): Does Macroeconomy Affect Bank Stability? A Review of Empirical Evidence, Journal of Banking Regulation, 9 (2): 102-115.

Wall, Larry D. and Timothy W. Koch (200o): Bank Loan-Loss Accounting: A Review of Theoretical and Empirical Evidence, Federal Reserve Bank of Atlanta Economic Review, 85 (2): 1-19. 


\section{Biographies}

Stefan Hlawatsch is a doctoral candidate at the department of Banking and Finance at the Otto-vonGuericke University Magdeburg. He graduated in Business Taxation and Banking and Finance (Otto-vonGuericke University of Magdeburg) in autumn 2008. His research interests include valuation, modeling and validation of credit risk parameters, shortcomings of Basel II and applications of risk models within banks.
Sebastian Ostrowski is a research and teaching assistant at the department of Banking and Finance at the Otto-von-Guericke University Magdeburg. He graduated in Operations Research and Banking and Finance (Otto-von-Guericke University of Magdeburg) in autumn 2007. Furthermore he is a student at the faculty of mathematics. His research interests include financial products containing derivatives and credit risk modeling. 